\title{
Amino-Functionalized Wood Aerogel for Efficient Removal of Copper Ions from Water
}

\author{
Junwang Meng, Hao Guan, Xinjian Dai, and Xiaoqing Wang \\ Research Institute of Wood Industry, Chinese Academy of Forestry, Beijing 100091, China \\ Correspondence should be addressed to Xiaoqing Wang; wangxq@caf.ac.cn
}

Received 19 May 2021; Accepted 5 June 2021; Published 18 June 2021

Academic Editor: Jingpeng Li

Copyright @ 2021 Junwang Meng et al. This is an open access article distributed under the Creative Commons Attribution License, which permits unrestricted use, distribution, and reproduction in any medium, provided the original work is properly cited.

\begin{abstract}
Developing bio-based adsorbents for efficient removal of heavy metal ions from water has attracted increasing attention due to their abundance, low cost, and sustainability. However, most of these adsorbents are in powdered or granular forms, suffering from difficult regeneration and poor recyclability. Here, we report a highly porous three-dimensional amino-functionalized wood aerogel for efficient heavy metal adsorption. The amino-functionalized wood aerogel was prepared from natural balsa wood via a delignification treatment, followed by TEMPO-mediated oxidation of the delignified wood and then grafting polyethylenimine (PEI) onto the oxidized cellulose skeleton. The obtained amino-functionalized wood aerogel possessed a unique porous lamellar structure with a low bulk density of $77.2 \mathrm{mg} / \mathrm{cm}^{3}$ and high porosity of $94.9 \%$. Benefiting from its high porosity and the introduced amino groups on the cellulose skeleton, the amino-functionalized wood aerogel exhibited a maximum $\mathrm{Cu}(\mathrm{II})$ adsorption capacity of $59.8 \mathrm{mg} \cdot \mathrm{g}^{-1}$, which was significantly higher than those of the TEMPO-oxidized wood aerogel and natural balsa wood. The adsorption process can be well described by the pseudo-second-order and Langmuir isotherm models, indicating that the $\mathrm{Cu}(\mathrm{II})$ adsorption by the PEI@wood aerogel was dominated by a monolayer chemisorption process. The developed amino-functionalized wood aerogel provides new insights for the design of efficient and low-cost monolithic absorbents for heavy metal remediation.
\end{abstract}

\section{Introduction}

Heavy metal ions (e.g., $\mathrm{Cu}(\mathrm{II}), \mathrm{Pb}(\mathrm{II})$, and $\mathrm{Cd}(\mathrm{II})$ ) discharged from industrial wastewater have become one of the major sources of water pollution worldwide, causing harmful impacts on the water environment and human health due to their high toxicity and nondegradability [1]. To date, various approaches, including ion exchange, membrane filtration, chemical precipitation, flocculation, bioremediation, and adsorption, have been adopted to remove heavy metal ions from wastewater [2]. Among these methods, adsorption is considered as one of the most promising approaches due to its advantages of low cost, high efficiency, and simple operation $[3,4]$. Some commonly used adsorbents, such as activated carbon, clay, synthetic polymers, and metal oxides, suffer from low adsorption capacity, high cost, and nondegradability, making them less attractive in practical applications [5]. Bio-based adsorbents, including sawdust, bark, straw, and cellulose, have attracted increasing interest as cheap and sustainable alternatives in wastewater treatment due to their abundance, low cost, and ecofriendliness $[6,7]$. However, most of these adsorbents are in powdered or granular forms, often causing separation and reuse difficulties in actual wastewater treatment. Therefore, developing monolithic adsorbents based on low-cost biomass resources for efficient heavy metal ion removal is highly desirable given their easy separation and recovery in the practical application.

As a renewable, sustainable, and ecofriendly natural material, wood represents a 3D hierarchical structure composed of numerous aligned hollow fibers along its growth direction. The hydrophilic and porous structure (e.g., tracheids, vessels, and pits) of natural wood provides multichannels for water and ion transport to support photosynthesis and transpiration in living trees [8]. Meanwhile, the main cell wall components of wood (i.e., cellulose, hemicelluloses, and lignin) contain a large number of functional groups (e.g., hydroxyl and carboxyl groups) that have the potential to be further functionalized to introduce metal-binding sites [9]. 
However, the natural wood lacks strong binding sites for heavy metal ions, resulting in limited adsorption capacity. Recently, bulk beech wood was functionalized with carboxyl groups $(-\mathrm{COOH})$ by esterification using anhydrides as a bioadsorbent for the remediation of copper ions from water [10]. The COOH-modified wood adsorbent could remove up to $95 \%$ of copper ions from low-concentration aqueous solutions. However, the poor accessibility of carboxyl groups located deep inside the wood cell walls limits the adsorption capacity of the modified beech wood. Therefore, it is necessary to increase the wood porosity and introduce more efficient functional groups to improve the adsorption capacity of natural wood toward heavy metal ions.

In this study, we developed a highly porous threedimensional amino-functionalized wood aerogel as an efficient bioadsorbent for copper (II) removal. The natural balsa wood was first delignified to remove lignin and hemicelluloses from the cell walls to enhance the porosity and specific surface area of the wood scaffold, thus increasing the contact area between adsorbents and heavy metal ions. In a subsequent step, the cellulose skeleton of the wood scaffold was oxidized to introduce carboxyl groups using the TEMPO/$\mathrm{NaClO} / \mathrm{NaBr}$ system and polyethylenimine (PEI) was then grafted onto the oxidized cellulose skeleton to introduce amino groups, which could serve as strong binding sites for chelating copper ions in aqueous solutions. The structure, morphology, chemical composition, and $\mathrm{Cu}(\mathrm{II})$ adsorption capacity of the amino-functionalized wood aerogel were investigated. Moreover, the adsorption mechanism was explored by adsorption kinetics and isotherm models. The proposed strategy opens up a new avenue for developing cost-effective wood-based monolithic absorbents for heavy metal remediation.

\section{Materials and Methods}

2.1. Materials. Balsa wood (Ochroma pyramidale) was cut into samples with the dimension of $20 \times 20 \times 5 \mathrm{~mm}^{3}$ (radial $\times$ tangential $\times$ longitudinal). Sodium chlorite $\left(\mathrm{NaClO}_{2}\right)$ $(80 \%)$, acetic acid, sodium hydroxide $(\mathrm{NaOH})$, hydrochloric acid $(\mathrm{HCl})(37 \%)$, sodium bromide $(\mathrm{NaBr})$, sodium hypochlorite $(\mathrm{NaClO}), 2,2,6,6$-teramethyl-1-piperdinyloxy radical (TEMPO), polyethylenimine (PEI) (molecular weight of $75000 \mathrm{Da}$ ), n-hydroxysuccinimide (NHS), 1-ethyl-3 (3dimethylaminopropyl) carbodiimide hydrochloride (EDC), and copper sulfate pentahydrate $\left(\mathrm{CuSO}_{4} \cdot 5 \mathrm{H}_{2} \mathrm{O}\right)$ were purchased from Aladdin Chemistry Co. Ltd. (Shanghai, China). All of the chemicals were used as received without further purification. Deionized (DI) water was used throughout the experiments.

2.2. Preparation of Delignified Wood Scaffold. Wood aerogel was prepared according to our previously reported method [11]. Briefly, the balsa wood samples were first treated with an aqueous solution of $2 \mathrm{wt} \% \mathrm{NaClO}_{2}$ buffered with acetic acid at $\mathrm{pH} 4.6$ for $6 \mathrm{~h}$ at $80^{\circ} \mathrm{C}$ for the removal of lignin. The delignified wood samples were then transferred into an aqueous solution of $8 \mathrm{wt} \% \mathrm{NaOH}$ and kept at $80^{\circ} \mathrm{C}$ for $8 \mathrm{~h}$ to further remove hemicelluloses. Finally, the samples were carefully rinsed with DI water to remove the chemical residues and stored in DI water.

2.3. Preparation of PEI@Wood Aerogel. To graft PEI onto the cellulose skeleton, the as-prepared delignified wood scaffold was oxidized using the TEMPO/NaClO/NaBr system to introduce carboxyl groups. Typically, the delignified wood samples $(10 \mathrm{~g}$ ) were immersed in $200 \mathrm{ml}$ of aqueous solution containing $0.2 \mathrm{~g}$ of TEMPO and $1.5 \mathrm{~g}$ of $\mathrm{NaBr}$. Then, $80 \mathrm{ml}$ of $\mathrm{NaClO}$ solution was added dropwise to the solution to initiate the oxidization reaction. The $\mathrm{pH}$ value of the solution was maintained at 10.0 by adding $0.1 \mathrm{M} \mathrm{NaOH}$. The reaction was terminated after $8 \mathrm{~h}$ by adding $0.5 \mathrm{M} \mathrm{HCl}$ to adjust the $\mathrm{pH}$ value to neutral. The resulting TEMPO-oxidized wood scaffolds were then washed with DI water for subsequent PEI grafting. Specifically, the TEMPO-oxidized samples $(10 \mathrm{~g})$ were soaked in $30 \mathrm{ml}$ of aqueous solution containing 15 wt $\%$ of branched PEI for $12 \mathrm{~h}$. Then, the soaked samples were transferred into an aqueous solution containing $500 \mathrm{mg}$ of NHS and $500 \mathrm{mg}$ of EDC and kept for $8 \mathrm{~h}$ at room temperature to initiate the amidation reaction. The obtained samples were washed three times with DI water and freeze dried at $-56^{\circ} \mathrm{C}$ for $36 \mathrm{~h}$ using a freeze dryer (Scientz-10N, Ningbo Scientz Biotechnology Co. Ltd., China), resulting in the formation of amino-functionalized wood aerogel (PEI@wood aerogel). The TEMPO-oxidized wood aerogels were also prepared by freeze drying for comparison.

2.4. Characterization. The surface morphology and structure of the samples were examined by field emission scanning electron microscopy (Hitachi SU-8010, Tokyo, Japan) equipped with an energy-dispersive X-ray spectroscopic detector for mapping. Fourier transform infrared (FT-IR) spectra were recorded on a Nicolet 6700 spectrometer (Thermo Scientific, Waltham, MA, USA) equipped with an ATR module over the scan range of $400-4000 \mathrm{~cm}^{-1}$. The X-ray photoelectron spectroscopy (XPS) measurements were performed on a Thermo ESCALAB 250Xi spectrometer (Thermo Scientific, USA) with a monochromatic $\mathrm{Al} \mathrm{K} \alpha \mathrm{X}$-ray source. The specific surface area was calculated using the Brunauer-Emmett-Teller (BET) method by a nitrogen adsorption apparatus (ASAP 2460, USA). The concentration of $\mathrm{Cu}(\mathrm{II})$ in the aqueous solutions was determined by ICP-MS (Agilent 7500ce, USA).

The apparent density $\left(\rho_{a}\right)$ of the sample was determined from the ratios of mass to volume and calculated according to the following equation:

$$
\rho_{a}=m / V
$$

where $m(\mathrm{~g})$ and $V\left(\mathrm{~cm}^{3}\right)$ represent the mass and volume of the sample, respectively. The porosity of the sample was calculated according to the following equation:

$$
\text { Porosity }(\%)=\left(1-\frac{\rho_{a}}{\rho_{c}}\right) \times 100 \% \text {, }
$$

where $\rho_{c}$ represents the cell wall density $\left(1.5 \mathrm{~g} \cdot \mathrm{cm}^{-3}\right)$. 
2.5. Adsorption Experiment. The $\mathrm{Cu}(\mathrm{II})$ adsorption experiments were conducted at room temperature. Firstly, an aqueous solution of $\mathrm{Cu}$ (II) with a concentration of $200 \mathrm{ppm}$ was prepared using $\mathrm{CuSO}_{4} \cdot 5 \mathrm{H}_{2} \mathrm{O}$ and the initial $\mathrm{pH}$ of the solution was controlled at 5.0. Then, the wood aerogel adsorbents were soaked in the solution for $12 \mathrm{~h}$ until the color of the sample turned dark blue. After adsorption, the $\mathrm{Cu}$ (II) concentrations of the solution were measured by ICP-MS and the $\mathrm{Cu}(\mathrm{II})$ adsorption capacity was calculated using the following equation:

$$
q_{e}=\frac{\left(C_{0}-C_{e}\right) V}{M}
$$

where $C_{0}\left(\mathrm{mg} \cdot \mathrm{l}^{-1}\right)$ and $C_{e}\left(\mathrm{mg} \cdot \mathrm{l}^{-1}\right)$ represent the $\mathrm{Cu}(\mathrm{II})$ concentrations in the initial and after adsorption, respectively; $q_{e}$ $\left(\mathrm{mg} \cdot \mathrm{g}^{-1}\right)$ represents the equilibrium adsorption amount, $V$ (l) is the volume of the solution, and $M(\mathrm{~g})$ represents the dosage of the adsorbents.

2.5.1. Adsorption Kinetics Study. $50 \mathrm{mg}$ wood aerogel adsorbents were immersed in $50 \mathrm{ml} \mathrm{Cu(II)}$ solutions with a concentration of $150 \mathrm{ppm}$ until the adsorption reached equilibrium. The initial $\mathrm{pH}$ of the solution was controlled at 5.0. At a predetermined time interval, the solution was collected to determine its $\mathrm{Cu}(\mathrm{II})$ concentration by ICP-MS. The adsorption data were fitted using the pseudo-first-order and the pseudo-second-order models as follows:

$$
\begin{aligned}
\ln \left(q_{e}-q_{t}\right) & =\ln q_{e}-k_{1} t \\
\frac{\mathrm{t}}{q_{t}} & =\frac{1}{k_{2} q_{e}^{2}}+\frac{t}{q_{e}},
\end{aligned}
$$

where $q_{e}\left(\mathrm{mg} \mathrm{g}^{-1}\right)$ and $q_{t}\left(\mathrm{mg} \cdot \mathrm{g}^{-1}\right)$ represent the $\mathrm{Cu}(\mathrm{II})$ adsorption capacity at the equilibrium and time $t$ (min), respectively, and $k_{1}\left(\mathrm{~min}^{-1}\right)$ and $k_{2}\left(\mathrm{~g} \cdot \mathrm{mg}^{-1} \cdot \mathrm{min}^{-1}\right)$ are the rate constants for the pseudo-first-order pseudo-secondorder equations, respectively.

2.5.2. Adsorption Isotherm Study. $50 \mathrm{mg}$ wood aerogel adsorbents were immersed in $50 \mathrm{ml} \mathrm{Cu(II)}$ solutions with a concentration ranging from 20 to $200 \mathrm{ppm}$ to study the adsorption isotherm. The adsorption experiments were carried out at room temperature with an initial $\mathrm{pH}$ of 5.0. The $\mathrm{Cu}(\mathrm{II})$ adsorption behavior was described by Langmuir and Freundlich isotherm models as follows:

$$
\begin{aligned}
\frac{C_{e}}{q_{e}} & =\frac{1}{k_{L} q_{m}}+\frac{C_{e}}{q_{m}}, \\
\log q_{e} & =\log K_{f}+\left(\frac{1}{n}\right) \log C_{e},
\end{aligned}
$$

where $q_{e}\left(\mathrm{mg} \cdot \mathrm{g}^{-1}\right)$ and $q_{m}\left(\mathrm{mg} \cdot \mathrm{g}^{-1}\right)$ represent the equilibrium and the maximum adsorption of samples, respectively, $C_{e}\left(\mathrm{mg} \cdot \mathrm{l}^{-1}\right)$ is the equilibrium concentration of $\mathrm{Cu}(\mathrm{II})$, and $K_{L}\left(1 \cdot \mathrm{mg}^{-1}\right)$ is the Langmuir constant. $K_{f}\left(\mathrm{~g} \cdot \mathrm{mg}^{-1}\right)$ is the Freundlich constant and $1 / n$ represents the empirical parameter.

\section{Results and Discussion}

3.1. Preparation and Characterization. The preparation process of the PEI@wood aerogel is illustrated in Figure 1(a). Natural balsa wood was used as starting materials to prepare the aerogel due to its low density $\left(\sim 220 \mathrm{mg} \cdot \mathrm{cm}^{-3}\right)$ and high porosity $(\sim 85.6 \%)$. To further enhance the porosity and specific surface area of the natural wood, lignin and hemicelluloses were removed from the cell walls by the aqueous solutions of $\mathrm{NaClO}_{2}$ and $\mathrm{NaOH}$, respectively. To improve the affinity of the natural wood towards heavy metal ions, the cellulose skeleton of the delignified wood was oxidized to introduce carboxyl groups via TEMPO-mediated oxidation. PEI was then grafted onto the cellulose skeleton via an amidation reaction of the introduced carboxyl groups with the amino groups of PEI [12]. The grafted PEI within the wood aerogel possesses large amounts of amino groups, which are expected to provide strong binding sites for $\mathrm{Cu}$ (II) adsorption.

The morphologies and structures of the natural wood, TEMPO-oxidized wood aerogel, and PEI@wood aerogel are shown in Figures 1(b)-1(d). The natural balsa wood has a honeycomb-like porous structure with thin cell walls. After chemical treatment and TEMPO oxidation, the natural wood changed its color from yellowish to white and the original honeycomb-like porous structure evolved into a lamellar structure (Figures 1(b) and 1(c)). This unique architecture was formed by the breakage of the thin cell walls during the chemical treatment and the eventual release of the broken cell walls during the freeze drying process [11]. Due to the removal of the cell wall matrix, the TEMPO-oxidized wood aerogel exhibited a low density of $\sim 58.1 \mathrm{mg} \cdot \mathrm{cm}^{-3}$, high porosity of $\sim 96.1 \%$, and high BET surface area of $\sim 17.3 \mathrm{~m}^{2} \cdot \mathrm{g}^{-1}$ (Table 1). The aligned cellulose nanofibers in the cell walls were fully exposed after the removal of cell wall matrix, which was beneficial for the subsequent functional modification. After grafting with PEI, the lamellar structure of the PEI@wood aerogel was well preserved and the color of the wood aerogel was changed from white to yellow (Figure 1(d)). Note that the density, porosity, and BET surface area of the wood aerogel varied slightly after PEI grafting. Energy dispersive $\mathrm{X}$-ray spectroscopy (EDX) analyses were performed to examine the distribution of PEI within the wood aerogel. Elemental mapping images of the PEI@wood aerogel revealed the uniform distribution of nitrogen (green) on both cross and radial sections, indicating that PEI was successfully grafted onto the cellulose skeleton of the wood aerogel (Figures 1(e) and 1(f)).

FT-IR analysis was performed to confirm the compositional changes in the wood samples subjected to different chemical treatments. Figure 2(a) shows the FT-IR spectra of the natural wood, wood aerogel, TEMPO-oxidized wood aerogel, and PEI@wood aerogel. The characteristic peaks of lignin at 1462,1505 , and $1593 \mathrm{~cm}^{-1}$ and hemicelluloses at 1235 and $1736 \mathrm{~cm}^{-1}$ in the FT-IR spectrum of the wood aerogel vanished after the chemical treatment, confirming the successful removal of lignin and hemicelluloses from the wood cell walls [11]. After TEMPO oxidation, the TEMPOoxidized wood aerogel showed two distinct and intense peaks 


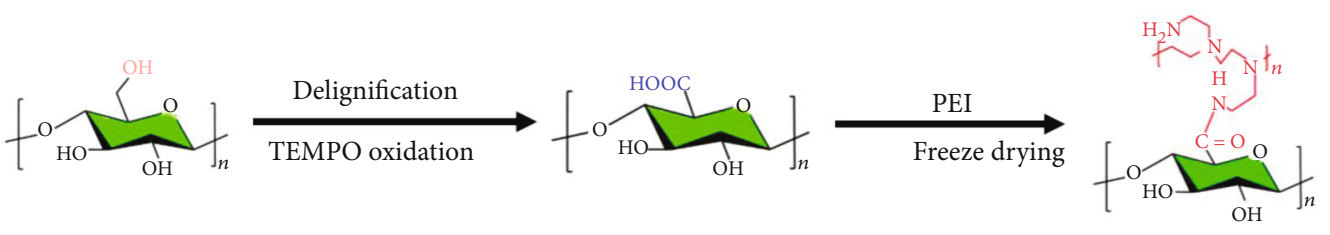

(a)

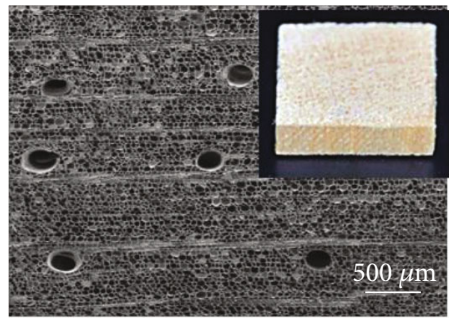

(b)
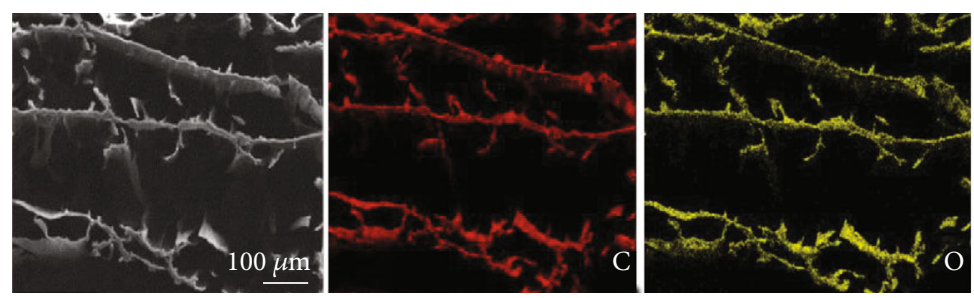

(e)
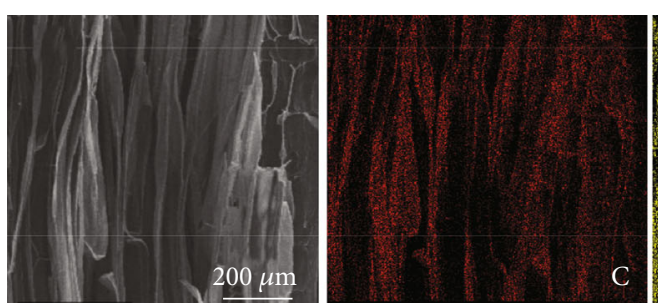

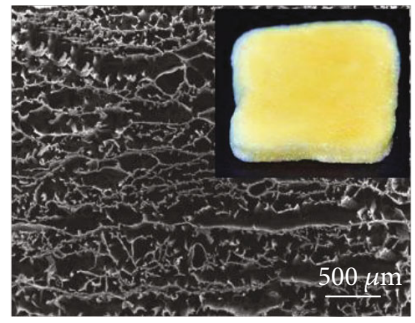

(d)
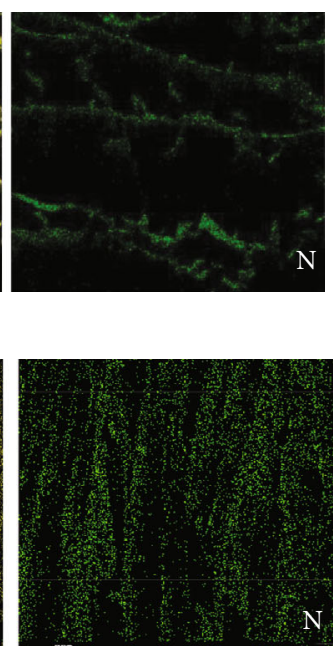

(f)

Figure 1: (a) Preparation process of the PEI@wood aerogel; (b-d) SEM images of the natural wood, TEMPO-oxidized wood aerogel, and PEI@wood aerogel; (e and f) EDX mapping images of the cross and radial sections of PEI@wood aerogel.

TABLE 1: Apparent density, porosity, and specific surface area of natural wood, TEMPO-oxidized wood aerogel, and PEI@wood aerogel.

\begin{tabular}{lccc}
\hline Sample & Apparent density $\left({\left.\mathrm{mg} \cdot \mathrm{cm}^{-3}\right)}\right.$ & Porosity $(\%)$ & Specific surface ${\operatorname{area~}\left(\mathrm{m}^{2} \cdot \mathrm{g}^{-1}\right)}^{-1}$ \\
\hline Natural wood & $220 \pm 4.3$ & $85.6 \pm 0.31$ & 0.37 \\
TEMPO-oxidized wood aerogel & $58.1 \pm 1.2$ & $96.1 \pm 0.03$ & 17.3 \\
PEI@wood aerogel & $77.2 \pm 5.5$ & $94.9 \pm 0.36$ & 12.1 \\
\hline
\end{tabular}

at $1400 \mathrm{~cm}^{-1}$ and $1600 \mathrm{~cm}^{-1}$, indicating that the primary hydroxyl groups of cellulose skeleton were successfully oxidized into carboxylic groups $[13,14]$. After further grafting with PEI, new characteristic peaks appeared at $1460 \mathrm{~cm}^{-1}$ and $1642 \mathrm{~cm}^{-1}$ in the spectrum of the PEI@wood aerogel, which can be associated with the formation of amide bond (-NH-CO-) [12]. Besides, the intensity of the peak at 815 $\mathrm{cm}^{-1}$ increased, which is assigned to the $\mathrm{N}-\mathrm{H}$ wagging vibration of $-\mathrm{NH}_{2}$ [15]. All these results demonstrated that PEI was successfully grafted onto the cellulose skeleton of the wood aerogel.
The surface compositional changes of the wood samples were further analyzed by XPS. As shown in Figure 2(b), the XPS spectra of the natural wood and TEMPO-oxidized wood aerogel show two characteristic peaks of $C 1$ s and $O 1$ s and the $O / C$ ratio was increased after TEMPO oxidation. After grafting with PEI, the binding energy peaks of $N$ 1s at 397$403 \mathrm{eV}$ appeared in the spectrum of PEI@wood aerogel, further confirming the successful introduction of PEI into the wood aerogel. The deconvolution of the narrow $N$ 1s peak revealed three splitting peaks of binding energy at 398.78, 399.46, and $401.09 \mathrm{eV}$, which could be assigned to the 


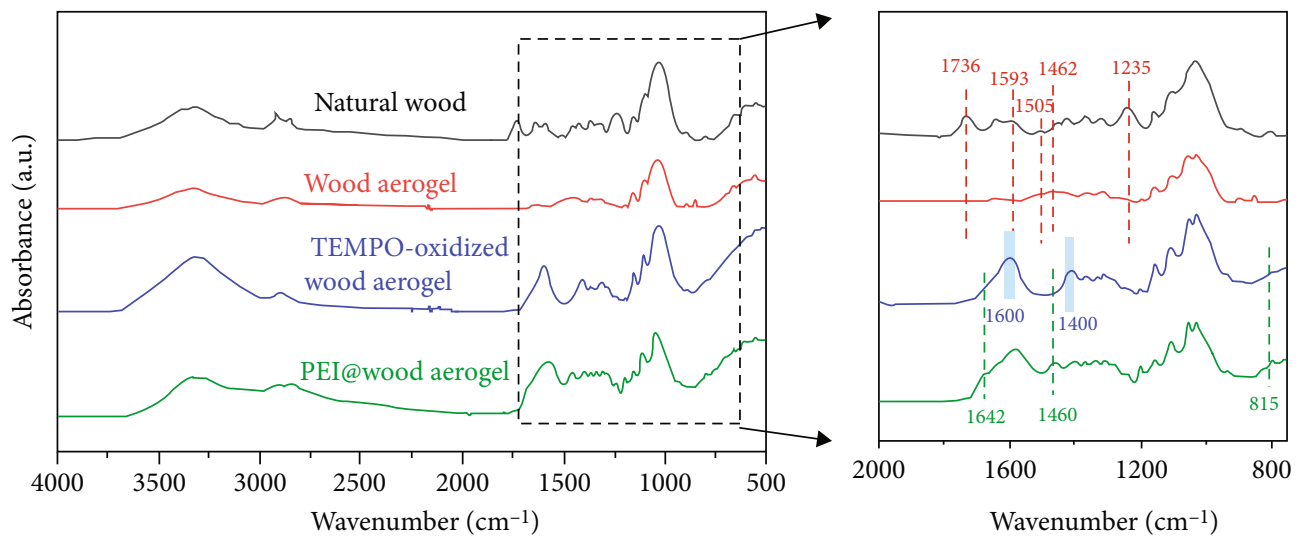

(a)

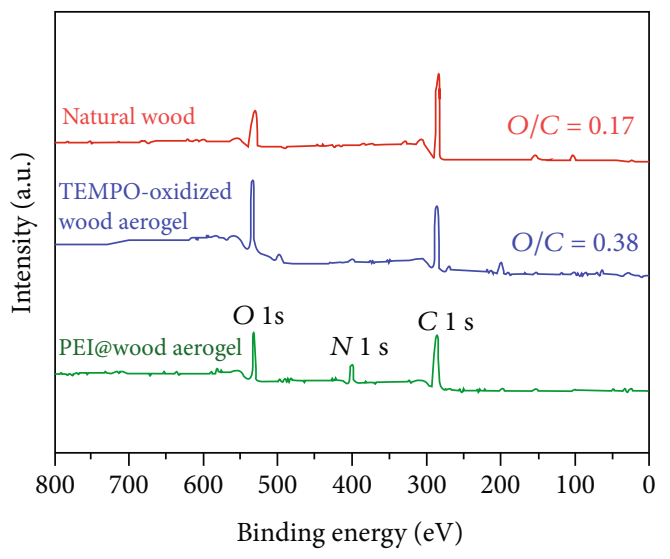

(b)

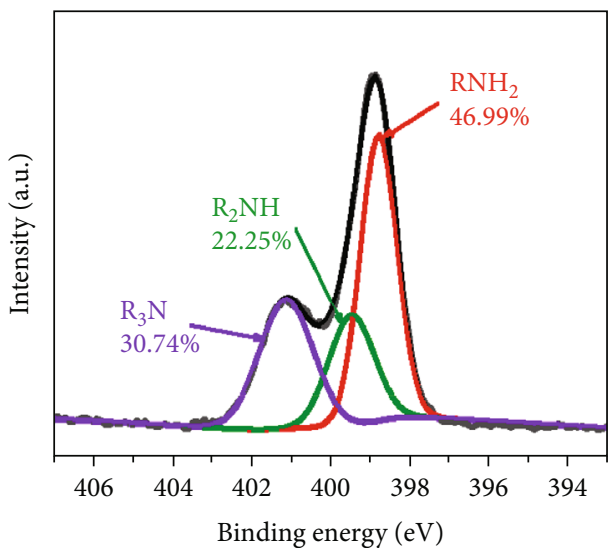

(c)

FIGURE 2: (a) FT-IR spectra of the natural wood, wood aerogel, TEMPO-oxidized wood aerogel, and PEI@wood aerogel; (b) XPS survey spectra of natural wood, TEMPO-oxidized wood aerogel, and PEI@wood aerogel; (c) N 1s spectrum of PEI@wood aerogel.

primary amino, secondary amino, and tertiary amino groups, respectively (Figure 2(c)) [16].

3.2. Cu(II) Adsorption Experiments. We compared the adsorption capacity of the natural wood, TEMPO-oxidized wood aerogel, and PEI@wood aerogel for Cu(II). As shown in Figure 3(a), the natural wood exhibited a poor $\mathrm{Cu}(\mathrm{II})$ adsorption capacity of only $4.1 \mathrm{mg} \cdot \mathrm{g}^{-1}$ due to its compact cell wall structure and limited chelating ability of hydroxyl groups towards $\mathrm{Cu}(\mathrm{II})$. The delignification and TEMPO oxidation treatment resulted in a higher $\mathrm{Cu}(\mathrm{II})$ adsorption capacity (15.0 mg.g ${ }^{-1}$ ) of the TEMPO-oxidized wood aerogel. This might be attributed to the increased porosity and specific surface area of the wood aerogel, allowing full infiltration of the $\mathrm{Cu}$ (II) solution into the porous structure of wood, which enhanced the accessibility of $\mathrm{Cu}$ (II) to the binding sites of the adsorbent. On the other hand, the carboxyl groups formed on the cellulose skeleton during TEMPO oxidation could absorb $\mathrm{Cu}$ (II) in the solution due to the electrostatic attraction effect. In contrast, the PEI@wood aerogel exhibited a high $\mathrm{Cu}(\mathrm{II})$ adsorption capacity of $48.4 \mathrm{mg} \cdot \mathrm{g}^{-1}$, which can be attributed to the large amounts of amino groups introduced after PEI grafting, providing more binding sites for $\mathrm{Cu}(\mathrm{II})$ adsorption. Figure 3(b) shows that when a small piece of PEI@wood aerogel was placed in the $\mathrm{Cu}(\mathrm{II})$ solution, it rapidly absorbed the $\mathrm{Cu}$ (II) in the solution and gradually turned dark-blue, indicating its desirable adsorption performance, which is better than that of the previously reported $\mathrm{COOH}$-modified beech wood [10]. The interaction between amino groups and $\mathrm{Cu}(\mathrm{II})$ was investigated by FTIR. As shown in Figure 3(c), a new intense peak appeared at $620 \mathrm{~cm}^{-1}$ in the spectrum of the PEI@wood aerogel after $\mathrm{Cu}$ (II) adsorption, which might be attributed to the complexation between amino groups and $\mathrm{Cu}(\mathrm{II})$ [17]. In addition, the peaks at $1642 \mathrm{~cm}^{-1}$ assigned to $\mathrm{N}-\mathrm{H}$ bending vibration disappeared, further indicating the chelation of $\mathrm{Cu}(\mathrm{II})$ to the amino groups.

The initial $\mathrm{pH}$ of the $\mathrm{Cu}(\mathrm{II})$ solution has a critical effect on the adsorption performance of the adsorbents. Figure 3(d) shows the $\mathrm{Cu}(\mathrm{II})$ adsorption capacity of the PEI@wood aerogel at different pH levels. When the pH was low, the high $\mathrm{H}^{+}$concentration caused strong electrostatic repulsive force between positively charged PEI and copper ions, leading to a low adsorption capacity [18]. With an increase of $\mathrm{pH}$ value from 3.0 to 5.0 , the $\mathrm{Cu}$ (II) adsorption capacity of the wood aerogel demonstrated a rapid rising trend. This phenomenon could be attributed to the deprotonation of the amino groups with increasing $\mathrm{pH}$, which 

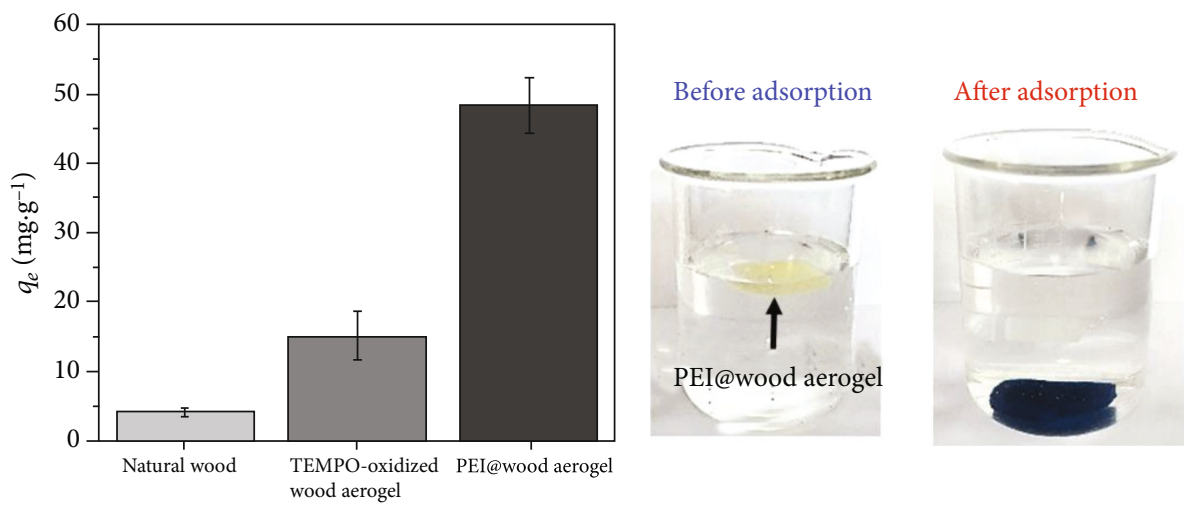

(a)

(b)
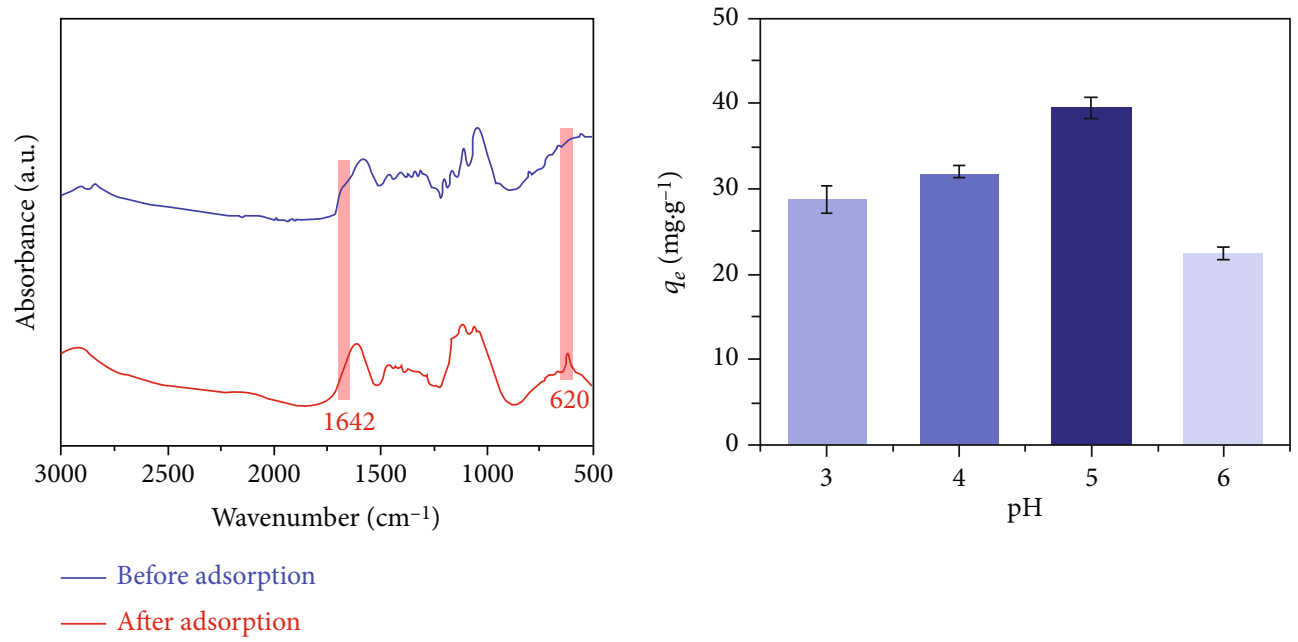

(c)

(d)

FIGURE 3: (a) Adsorption performance of natural wood, TEMPO-oxidized wood aerogel, and PEI@wood aerogel; (b) photographs of the PEI@wood aerogel before and after Cu(II) adsorption; (c) FT-IR spectra of the PEI@wood aerogel before and after Cu(II) adsorption; (d) effect of initial $\mathrm{pH}$ on the $\mathrm{Cu}(\mathrm{II})$ adsorption capacity.

facilitates the formation of chelates between amino groups and copper ions. However, when the initial pH was increased to 6.0 , the $\mathrm{Cu}(\mathrm{II})$ adsorption capacity decreased dramatically due to the precipitation of copper ions forming $\mathrm{Cu}(\mathrm{OH})_{2}$ [17]. Therefore, the initial $\mathrm{pH}$ of 5.0 could be regarded as the optimal $\mathrm{pH}$ for $\mathrm{Cu}(\mathrm{II})$ adsorption.

To further evaluate the adsorption process of $\mathrm{Cu}$ (II) by the adsorbents, the adsorption kinetics was investigated at a constant $\mathrm{pH}$ value of 5.0 under room temperature. Figure 4(a) shows the equilibrium adsorption capacity of the PEI@wood aerogel for $\mathrm{Cu}(\mathrm{II})$ as a function of adsorption time. It can be seen that the adsorption efficiency increased rapidly at the beginning $6 \mathrm{~h}$ of the experiment due to the large numbers of binding sites (amino and carboxyl groups) on the surface of the PEI@wood aerogel for $\mathrm{Cu}$ (II) adsorption. The adsorption capacity tended to be stabilized and reached equilibrium after $10 \mathrm{~h}$, indicating that adsorption sites were almost saturated.

Both the pseudo-first-order and pseudo-second-order kinetic models were used to fit the experimental data, and the fitting results and kinetic parameters are shown in Figure 4(a) and Table 2. The linear correlation coefficient
$\left(R^{2}\right)$ values for the pseudo-first-order and pseudo-secondorder kinetic models are 0.9560 and 0.9921 , respectively. The fitting results suggested that the adsorption process of the PEI@wood aerogel for Cu(II) could be better described by the pseudo-second-order kinetic model, indicating that the adsorption process was dominated by chemical adsorption. For the synthesized PEI@wood aerogel, the abundant amino and carboxyl groups on the cellulose skeleton could capture $\mathrm{Cu}(\mathrm{II})$ effectively via surface complexation and electrostatic interactions $[19,20]$.

To reveal the interactions between the adsorbent and adsorbate, as well as the theoretical maximum adsorption capacity of the PEI@wood aerogel for Cu(II) [21], we investigated the effect of initial $\mathrm{Cu}$ (II) concentration on the equilibrium adsorption capacity of the PEI@wood aerogel. Clearly, the equilibrium adsorption capacity increased rapidly at low $\mathrm{Cu}(\mathrm{II})$ concentration and then increased slowly when the concentration was above $100 \mathrm{ppm}$. The adsorption process was further fitted using the Langmuir and Freundlich isotherm models, and the fittings results and isotherm parameters are shown in Figure 4(b) and Table 3. Obviously, the Langmuir isotherm model better 


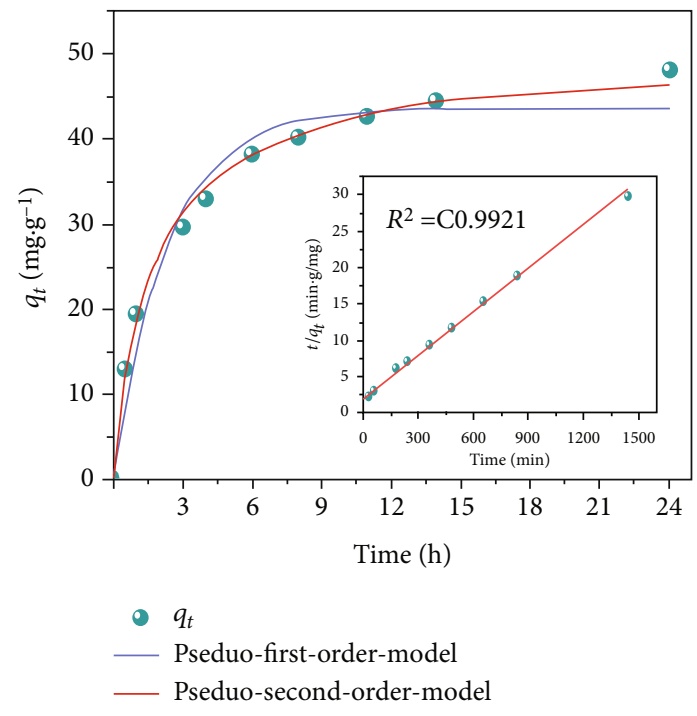

(a)

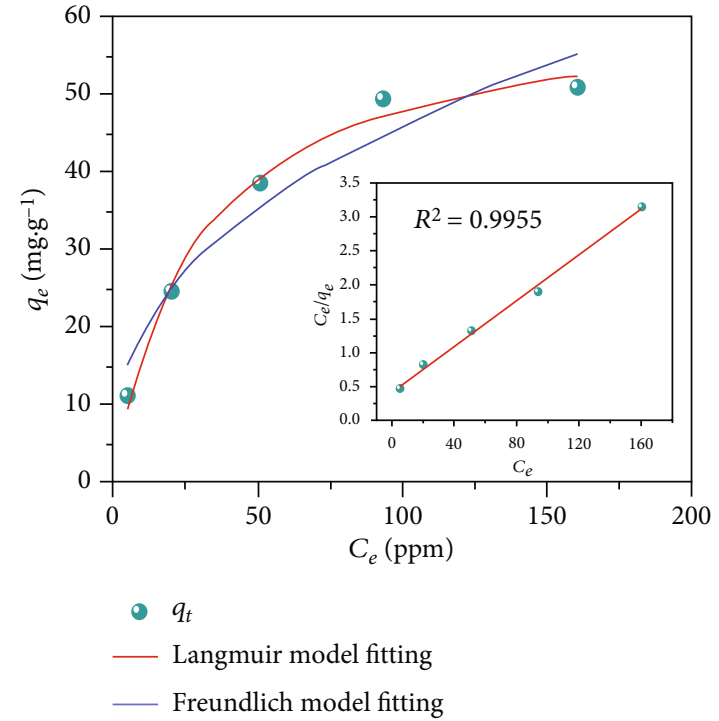

(b)

FIgURE 4: (a) Adsorption kinetics of PEI@wood aerogel for Cu(II). Inset: pseudo-second-order kinetic plot; (b) adsorption isothermal of PEI@wood aerogel for Cu(II). Inset: linear regression by fitting the data with the Langmuir adsorption model.

TABLE 2: Kinetic parameters for the adsorption of Cu(II) by PEI@wood aerogel.

\begin{tabular}{lcccccc}
\hline \multirow{2}{*}{ Sample } & \multirow{2}{*}{$q_{e, \text { exp }}\left(\mathrm{mg}^{-1} \mathrm{~g}^{-1}\right)$} & \multicolumn{3}{c}{ Pseudo-first-order kinetic model } & \multicolumn{3}{c}{ Pseudo-second-order kinetic model } \\
& $K_{1}\left(\mathrm{~min}^{-1}\right)$ & $q_{e, \text { cal }}\left(\mathrm{mg}^{-1}\right)$ & $R^{2}$ & $K_{1}\left(\mathrm{~g} \cdot \mathrm{mg}^{-1} \cdot \mathrm{min}^{-1}\right)$ & $q_{e, \mathrm{cal}}\left(\mathrm{mg}^{-1}\right)$ & $R^{2}$ \\
\hline PEI@wood aerogel & 48.45 & 0.0029 & 65.16 & 0.9560 & 0.019 & 48.71 \\
\hline
\end{tabular}

TABLE 3: Langmuir and Freundlich isotherm parameters for the adsorption of Cu(II) by PEI@wood aerogel.

\begin{tabular}{|c|c|c|c|c|c|c|}
\hline \multirow{2}{*}{ Sample } & \multicolumn{3}{|c|}{ Langmuir isotherm } & \multicolumn{3}{|c|}{ Freundlich isotherm } \\
\hline & $K_{L}\left(1 \cdot \mathrm{mg}^{-1}\right)$ & $q_{m}\left(\mathrm{mg} \cdot \mathrm{g}^{-1}\right)$ & $R^{2}$ & $K_{f}$ & $n$ & $R^{2}$ \\
\hline PEI@wood aerogel & 0.0388 & 59.88 & 0.9955 & 5.6406 & 2.16 & 0.9482 \\
\hline
\end{tabular}

described the adsorption data with a higher correlation coefficient $\left(R^{2}=0.9955\right)$, demonstrating that the adsorption sites were homogeneously distributed in the PEI@wood aerogel and the adsorption was a monolayer sorption process [22]. The Langmuir isotherm model was also used to calculate the maximum adsorption capacity of the PEI@wood aerogel for $\mathrm{Cu}(\mathrm{II})$, yielding a value of $59.8 \mathrm{mg} \cdot \mathrm{g}^{-1}$, which exceeds the experimental value of $48.4 \mathrm{mg} \cdot \mathrm{g}^{-1}$.

\section{Conclusions}

In summary, highly porous $3 \mathrm{D}$ amino-functionalized wood aerogel for $\mathrm{Cu}(\mathrm{II})$ adsorption was prepared from natural balsa wood by delignification treatment and subsequent grafting of PEI onto the cellulose skeleton of the wood aerogel. The as-prepared PEI@wood aerogel possessed a unique porous lamellar structure with a low bulk density (77.2 $\mathrm{mg} \cdot \mathrm{cm}^{-3}$ ) and high porosity (94.9\%). The introduced amino groups of PEI serve as the predominant active sites for $\mathrm{Cu}$ (II) adsorption, and the maximum adsorption capacity of the PEI@wood aerogel for $\mathrm{Cu}$ (II) was calculated to be 59.8 $\mathrm{mg} \cdot \mathrm{g}^{-1}$ based on the Langmuir isotherm model. The adsorption kinetics follows the pseudo-second-order model, and the adsorption process was dominated by chemical adsorption. The Langmuir isotherm model fits the adsorption data better than Freundlich model, suggesting that the $\mathrm{Cu}(\mathrm{II})$ adsorption by the PEI@wood aerogel was a monolayer adsorption process. This study provides a novel strategy for developing low-cost, efficient, and eco-friendly monolithic absorbents based on natural wood for removal of heavy metal ions from wastewater.

\section{Data Availability}

The data used to support the findings of this study are available from the corresponding author upon request. 


\section{Conflicts of Interest}

The authors declare no conflict of interest.

\section{Acknowledgments}

This work was financially supported by the Fundamental Research Funds for the Central Non-profit Research Institution of CAF (CAFYBB2020QA004).

\section{References}

[1] L. Mo, H. Pang, Y. Tan, S. Zhang, and J. Li, “3D multi-wall perforated nanocellulose-based polyethylenimine aerogels for ultrahigh efficient and reversible removal of $\mathrm{Cu}$ (II) ions from water," Chemical Engineering Journal, vol. 378, article 122157, 2019.

[2] L. Joseph, B. M. Jun, J. R. V. Flora, C. M. Park, and Y. Yoon, "Removal of heavy metals from water sources in the developing world using low- cost materials: a review," Chemosphere, vol. 229, pp. 142-159, 2019.

[3] G. Magnacca, A. Allera, E. Montoneri et al., "Novel magnetite nanoparticles coated with waste-sourced biobased substances as sustainable and renewable adsorbing materials," ACS Sustainable Chemistry \& Engineering, vol. 2, no. 6, pp. 15181524, 2014.

[4] L. Lihua, T. Li, G. G. Yang, Y. F. Wang, A. P. Tang, and Y. L. Ling, "Synthesis of thiol-functionalized mesoporous calcium silicate and its adsorption characteristics for heavy metal ions," Journal of Environmental Chemical Engineering, vol. 5, no. 6, pp. 6201-6215, 2017.

[5] H. Qin, T. Hu, Y. Zhai, N. Lu, and J. Aliyeva, "The improved methods of heavy metals removal by biosorbents: a review," Environmental Pollution, vol. 258, article 113777, 2020.

[6] H. Liu, Y. Wei, J. Luo et al., “3D hierarchical porous-structured biochar aerogel for rapid and efficient phenicol antibiotics removal from water," Chemical Engineering Journal, vol. 368, pp. 639-648, 2019.

[7] Y. Xiong, C. Wang, H. Wang et al., “A 3D titanate aerogel with cellulose as the adsorption-aggregator for highly efficient water purification," Journal of Materials Chemistry A, vol. 5, no. 12, pp. 5813-5819, 2017.

[8] C. Jia, Y. Li, Z. Yang et al., "Rich mesostructures derived from natural woods for solar steam generation," Joule, vol. 1, no. 3, pp. 588-599, 2017.

[9] T. Keplinger, X. Q. Wang, and I. Burgert, "Nanofibrillated cellulose composites and wood derived scaffolds for functional materials," Journal of Materials Chemistry A, vol. 7, no. 7, pp. 2981-2992, 2019.

[10] S. Vitas, T. Keplinger, N. Reichholf, R. Figi, and E. Cabane, "Functional lignocellulosic material for the remediation of copper(II) ions from water: towards the design of a wood filter," Journal of Hazardous Materials, vol. 355, pp. 119-127, 2018.

[11] H. Guan, Z. Y. Cheng, and X. Q. Wang, "Highly compressible wood sponges with a spring-like lamellar structure as effective and reusable oil absorbents," ACS Nano, vol. 12, no. 10, pp. 10365-10373, 2018.

[12] F. P. Zhao, E. Repo, Y. Song et al., "Polyethylenimine-crosslinked cellulose nanocrystals for highly efficient recovery of rare earth elements from water and a mechanism study," Green Chemistry, vol. 19, no. 20, pp. 4816-4828, 2017.
[13] H. Sehaqui, U. P. de Larraya, P. Liu et al., "Enhancing Adsorption of heavy metal ions onto biobased nanofibers from waste pulp residues for application in wastewater treatment," Cellulose, vol. 21, no. 4, pp. 2831-2844, 2014.

[14] Q. Y. Wu, C. W. Wang, R. L. Wang et al., "Salinity-gradient power generation with ionized wood membranes," Advanced Energy Materials, vol. 10, no. 1, pp. 1614-6832, 2020.

[15] C. X. Tang, P. Brodie, Y. Z. Li, N. J. Grishkewich, M. Brunsting, and K. C. Tam, "Shape recoverable and mechanically robust cellulose aerogel beads for efficient removal of copper ions," Chemical Engineering Journal, vol. 392, pp. 124821-128947, 2020.

[16] M. H. Min, L. D. Shen, G. S. Hong et al., "Micro-nano structure poly(ether sulfones)/poly(ethyleneimine) nanofibrous affinity membranes for adsorption of anionic dyes and heavy metal ions in aqueous solution," Chemical Engineering Journal, vol. 197, pp. 88-100, 2012.

[17] J. Liu, D. Su, J. Yao, Y. Huang, Z. Shao, and X. Chen, "Soy protein-based polyethylenimine hydrogel and its high selectivity for copper ion removal in wastewater treatment," Journal of Materials Chemistry A, vol. 5, no. 8, pp. 4163-4171, 2017.

[18] B. Wang, J. L. Wen, S. L. Sun et al., "Chemosynthesis and structural characterization of a novel lignin-based bio- sorbent and its strong adsorption for $\mathrm{Pb}(\mathrm{II})$," Industrial Crops and Products, vol. 108, pp. 72-80, 2017.

[19] J. Li, K. M. Zuo, W. B. Wu et al., "Shape memory aerogels from nanocellulose and polyethyleneimine as a novel adsorbent for removal of $\mathrm{Cu}(\mathrm{II})$ and $\mathrm{Pb}(\mathrm{II})$, " Carbohydrate Polymers, vol. 196, pp. 376-384, 2018.

[20] Y. Tan, K. L. Wang, Q. Yan, S. F. Zhang, J. Z. Li, and Y. Ji, "Synthesis of amino-functionalized waste wood flour adsorbent for high-capacity $\mathrm{Pb}(\mathrm{II})$ adsorption," ACS Omega, vol. 4, no. 6, pp. 10475-10484, 2019.

[21] J. Febrianto, A. N. Kosasih, J. Sunarso, Y. H. Ju, N. Indraswati, and S. Ismadji, "Equilibrium and kinetic studies in adsorption of heavy metals using biosorbent: a summary of recent studies," Journal of Hazardous Materials, vol. 162, no. 2-3, pp. 616-645, 2009.

[22] C. X. Tang, P. Brodie, M. Brunsting, and K. C. Tam, "Carboxylated cellulose cryogel beads via a one-step ester crosslinking of maleic anhydride for copper ions removal," Carbohydrate Polymers, vol. 242, p. 116397, 2020. 